\title{
Report of the Korean Association of External Quality Assessment Service on Autoimmune Testing (2018-2019)
}

\author{
Hee-Jung Chung ${ }^{1}$, Hee-Won Moon ${ }^{1}$, and Joowon $\mathrm{Yi}^{2}$ \\ ${ }^{1}$ Department of Laboratory Medicine, Konkuk University School of Medicine; 2Samkwang Medical Laboratories, Seoul, Korea
}

\section{Corresponding author:}

Hee-Won Moon

Department of Laboratory Medicine, Konkuk University Medical Center, 1201 Neungdong-ro, Gwangjin-gu, Seoul 05030, Korea

Tel +82-2-2030-5583

Fax +82-2-2030-7498

E-mail hannasis@hanmail.net

This is an Open Access article distributed under the terms of the Creative Commons Attribution Non-Commercial License (http://creativecommons.org/licenses/ by-nc/4.0) which permits unrestricted non-commercial use, distribution, and reproduction in any medium, provided the original work is properly cited.
Under the Korean Association of External Quality Assessment Service, autoimmune proficiency testings (PT) for six test items were performed in 2018-2019 for laboratory quality improvement. We conducted two trials per year and sent three PT materials for anti-nuclear antibody (ANA) testing and two PT materials for anti-mitochondrial antibody (AMA), anti-smooth muscle antibody (SMA), anti-thyroglobulin antibody (anti-Tg), anti-thyroperoxidase antibody (anti-TPO), and anti-double stranded DNA antibody (anti-dsDNA) testing in each trial. The analysis was conducted based on the information and results of each test item entered by the laboratory. The report comprised of a common report that showed the characteristics of all the participating laboratories and a laboratory-specific report that showed the assessment data of individual laboratories. The intended response rates for ANA, AMA, SMA, and anti-dsDNA qualitative tests were over $97.5 \%, 88.2 \%, 85.0 \%$, and $90.4 \%$, respectively. The coefficient of variations for anti-Tg and anti-TPO was $10.4 \%-70.1 \%$ and $16.6 \%-21.0 \%$, respectively. The number of participating laboratories in 2019 was more than that in 2018. We believe this statistical report will be useful to interpret external PT results and set up autoimmune assays at each laboratory.

(Lab Med Qual Assur 2020;42:1-9)

Key Words Korean Association of External Quality Assessment Service, Laboratory proficiency testing, Quality improvement, Immunology, Autoimmune diseases, Autoimmune antibodies

\section{서론}

대한임상검사정도관리협회(협회) 신빙도조사사업은 2016년 차 세대 신빙도조사사업으로 대폭 개편하여 검사실 품질향상을 위해 노력하고 있다[1]. 6 개의 분야 중 진단면역학분야의 신빙도조사는 2017년에는 보체•면역글로불린검사, 감염성 항원•항체검사, 감 염성 반응검사의 3개 프로그램 중분류만 운영되었고, 2018년부터 조직적합성검사, 세포면역검사, 자가면역검사 3 개 프로그램 중분 류가 추가되어 총 6개 프로그램 중분류가 운영되었다. 2018년부 터 추가된 3 개 프로그램 중분류 중 하나인 자가면역검사 프로그램
은 자가면역질환 I, II의 세분화된 프로그램으로 구성된다. 저자들 은 2018년도와 2019년도에 시행한 자가면역검사 신빙도조사사 업 내용과 결과를 보고하고자 한다.

\section{재료 및 방법}

\section{1. 검사항목}

자가면역검사 프로그램은 2018년과 2019년 각각 연 2회 에 걸쳐 신빙도조사사업을 수행하였다. 자가면역검사 프로그 램에서는 총 6 개의 검사항목에 대하여 신빙도조사를 실시하였 
다. 자가면역질환 I 프로그램(autoimmune antibodies I)은 간 접면역형광법으로 시행하는 anti-nuclear antibody (ANA), anti-mitochondrial antibody (AMA), anti-smooth muscle antibody (SMA) 3개 항목이며, 자가면역질환 II 프로그램 (autoimmune antibodies II)은 장비로 정량결과를 측정하는 anti-thyroglobulin antibody (anti- $\mathrm{Tg}$ ), anti-thyroperoxidase antibody (anti-TPO), anti-double stranded DNA antibody (anti-dsDNA) 3개 검사항목이다(Table 1).

\section{2. 외부신빙도조사 물질}

외부신빙도조사 물질로는 2018년에는 상품화된 정도관리 물질을 사용하였다. Anti-dsDNA 검사항목은 dsDNA Control (Omega Diagnostics, Littleport Cambridgeshire, UK)을, 나 머지 5개 검사항목은 Liquichek Autoimmune Control (BioRad Laboratories, Hercules, CA, USA)을 사용하였다. 2019년 에는 자가제조한 외부신빙도조사 물질을 사용하였다. 외부신빙도 조사 물질의 개수는 ANA 항목만 회차당 3개의 물질을, 나머지 5

Table 1. Baseline data of proficiency tests for autoimmune antibodies, 2018-2019

\begin{tabular}{clll}
\hline Program & \multicolumn{1}{c}{ Tests } & Report form & Character \\
\hline Autoimmune antibodies I & ANA & Qualitative & Mandatory \\
\hline & & Pattern and titer in positive results & Educational challenge \\
\hline & AMA & Qualitative & Mandatory \\
\hline Sutoimmune antibodies II & Anti-Tg & Qualitative & Mandatory \\
\hline & Anti-TPO & Quantitative & Mandatory \\
\hline & Anti-dsDNA & Qualitative & Mandatory \\
\hline
\end{tabular}

Abbreviations: ANA, anti-nuclear antibody; AMA, anti-mitochondrial antibody; SMA, anti-smooth muscle antibody; anti-Tg, antithyroglobulin antibody; anti-TPO, anti-thyroperoxidase antibody; anti-dsDNA, anti-double strand DNA antibody.

Table 2. List of proficiency testing specimens used for autoimmune antibodies and timelines of each trial, 2018-2019

\begin{tabular}{|c|c|c|c|c|c|}
\hline \multirow{2}{*}{ Program } & \multirow{2}{*}{ Specifications } & \multicolumn{4}{|c|}{ Trial } \\
\hline & & 2018,1 st & 2018, 2nd & 2019,1 st & 2019, 2nd \\
\hline \multirow[t]{8}{*}{ Autoimmune antibodies I } & Delivery date & 2018. 4. 23 & 2018. 9. 10 & 2019.4. 1 & 2019. 10. 14 \\
\hline & Response date & 2018. 4. 23-5. 3 & 2018. 9. 10-9. 20 & 2019.4.1-4. 11 & 2019. 10. 14-10. 24 \\
\hline & Tests & & & & \\
\hline & ANA & IA1-18-01 & IA1-18-06 & $\mid A 1-19-01$ & IA1-19-06 \\
\hline & & IA1-18-02 & IA1-18-07 & IA1-19-02 & IA1-19-07 \\
\hline & & IA1-18-03 & IA1-18-08 & IA1-19-03 & IA1-19-08 \\
\hline & AMA and SMA & IA1-18-04 & IA1-18-09 & IA1-19-04 & IA1-19-09 \\
\hline & & IA1-18-05 & IA1-18-10 & IA1-19-05 & IA1-19-10 \\
\hline \multirow[t]{7}{*}{ Autoimmune antibodies II } & Delivery date & 2018. 4. 23 & 2018.9.10 & 2019. 4.1 & 2019.10. 14 \\
\hline & Response date & 2018. 4. 23-5. 3 & 2018. 9. 10-9. 20 & 2019.4.1-4. 11 & 2019. 10. 14-10. 24 \\
\hline & Tests & & & & \\
\hline & Anti-Tg and anti-TPO & IA2-18-01 & IA2-18-05 & IA2-19-01 & IA2-19-05 \\
\hline & & IA2-18-02 & IA2-18-06 & IA2-19-02 & IA2-19-06 \\
\hline & Anti-dsDNA & IA2-18-03 & IA2-18-07 & IA2-19-03 & IA2-19-07 \\
\hline & & IA2-18-04 & IA2-18-08 & IA2-19-04 & IA2-19-08 \\
\hline
\end{tabular}

Abbreviations: ANA, anti-nuclear antibody; AMA, anti-mitochondrial antibody; SMA, anti-smooth muscle antibody; anti-Tg, antithyroglobulin antibody; anti-TPO, anti-thyroperoxidase antibody; anti-dsDNA, anti-double strand DNA antibody. 
Table 3. Results of proficiency tests for qualitative autoimmune testing (ANA, AMA, SMA, and anti-dsDNA)

\begin{tabular}{|c|c|c|c|c|c|}
\hline \multirow{2}{*}{ Trial } & \multirow{2}{*}{ Tests } & \multirow{2}{*}{$\begin{array}{c}\text { No. of } \\
\text { participants }\end{array}$} & \multirow{2}{*}{ Specimen } & \multicolumn{2}{|c|}{ Response } \\
\hline & & & & Negative & Positive \\
\hline \multirow[t]{9}{*}{$2018,1 s t$} & ANA & 74 & IA1-18-01 & 0 & $74(100.0)$ \\
\hline & & & IA1-18-02 & $74(100.0)$ & 0 \\
\hline & & & IA1-18-03 & 0 & $74(100.0)$ \\
\hline & AMA & 20 & IA1-18-04 & $19(95.0)$ & $1(5.0)$ \\
\hline & & & IA1-18-05 & $1(5.0)$ & $19(95.0)$ \\
\hline & SMA & 20 & IA1-18-04 & $3(15.0)$ & $17(85.0)$ \\
\hline & & & IA1-18-05 & $19(95.0)$ & $1(5.0)$ \\
\hline & Anti-dsDNA & 46 & IA2-18-03 & $46(100.0)$ & 0 \\
\hline & & & IA2-18-04 & $1(2.2)$ & $45(97.8)$ \\
\hline \multirow[t]{9}{*}{ 2018, 2nd } & ANA & 72 & IA1-18-06 & $1(1.4)$ & $71(98.6)$ \\
\hline & & & IA1-18-07 & $72(100.0)$ & 0 \\
\hline & & & IA1-18-08 & 0 & $72(100.0)$ \\
\hline & AMA & 17 & IA1-18-09 & $2(11.8)$ & $15(88.2)$ \\
\hline & & & IA1-18-10 & $16(94.1)$ & $1(5.9)$ \\
\hline & SMA & 16 & IA1-18-09 & $15(93.8)$ & $1(6.3)$ \\
\hline & & & IA1-18-10 & $1(6.3)$ & $15(93.8)$ \\
\hline & Anti-dsDNA & 46 & IA2-18-07 & $46(100.0)$ & 0 \\
\hline & & & IA2-18-08 & $1(2.2)$ & $45(97.8)$ \\
\hline \multirow[t]{9}{*}{2019,1 st } & ANA & 77 & IA1-19-01 & 75 (97.5) & $2(2.5)$ \\
\hline & & & IA1-19-02 & 0 & $77(100.0)$ \\
\hline & & & IA1-19-03 & 0 & $77(100.0)$ \\
\hline & AMA & 19 & IA1-19-04 & $19(100.0)$ & 0 \\
\hline & & & IA1-19-05 & 0 & $19(100.0)$ \\
\hline & SMA & 19 & IA1-19-04 & $18(94.7)$ & $1(5.3)$ \\
\hline & & & IA1-19-05 & $19(100.0)$ & 0 \\
\hline & Anti-dsDNA & 52 & IA2-19-03 & $52(100.0)$ & 0 \\
\hline & & & IA2-19-04 & $5(9.6)$ & $47(90.4)$ \\
\hline \multirow[t]{9}{*}{ 2019, 2nd } & ANA & 77 & IA1-19-06 & $76(98.7)$ & $1(1.3)$ \\
\hline & & & IA1-19-07 & 0 & $77(100.0)$ \\
\hline & & & IA1-19-08 & 0 & $77(100.0)$ \\
\hline & AMA & 18 & IA1-19-09 & $18(100.0)$ & 0 \\
\hline & & & IA1-19-10 & 0 & $18(100.0)$ \\
\hline & SMA & 18 & IA1-19-09 & $18(100.0)$ & 0 \\
\hline & & & IA1-19-10 & $18(100.0)$ & 0 \\
\hline & Anti-dsDNA & 50 & IA2-19-07 & $50(100.0)$ & 0 \\
\hline & & & IA2-19-08 & $2(4.0)$ & $48(96.0)$ \\
\hline
\end{tabular}

Values are presented as number (\%), unless otherwise stated. Intended responses are indicated in bold.

Abbreviations: ANA, anti-nuclear antibody; AMA, anti-mitochondrial antibody; SMA, anti-smooth muscle antibody; anti-dsDNA, antidouble strand DNA antibody. 
개 항목은 모두 회차당 2 개의 물질을 발송하였다. 자가제조한 외 부신빙도조사 물질은 분주 $\rightarrow$ 표식(라벨) 부착 $\rightarrow$ 포장(냉동상태 가 유지될 수 있도록 제작된 아이스팩 내장 박스)단계를 거쳐 예정 된 배송일에 각 참여기관으로 발송되었다(Table 2).

\section{3. 결과 입력}

ANA, AMA, SMA, anti-dsDNA 검사항목의 경우 참여기관은 결과를 positive 또는 negative의 정성으로 응답하도록 하였다. Anti-Tg, anti-TPO 항목의 경우 정량결과를 응답하도록 하였다. Anti-dsDNA 항목은 정량결과가 측정되지만, 검사방법마다 단위 및 수치가 차이가 크기 때문에 정성결과로만 응답하도록 하였다. ANA 항목의 pattern 및 titer는 교육목적으로 응답하도록 하였다 (Table 1). 참여기관은 프로그램 안내문에 따라 검체 수령 후 가능 한 빨리 검사 수행 후 지정된 회신 마감일 이내에 대한임상검사정 도관리협회 신빙도조사사업 홈페이지(http://eqas.keqas.org)에 결과를 입력하도록 하였다(Table 2).

\section{4. 결과 판정 및 분석}

신빙도조사 결과보고서는 자가면역질환 I 프로그램, 자가면역 질환 II 프로그램에 대하여 각각 작성하였다. 보고서는 전체 참여 기관의 특성을 보여주는 공통보고서와 개별기관의 평가자료를 보 여주는 기관별 보고서로 나누어 작성하였다. 정성검사(자가면역
질환 I의 ANA, AMA, SMA 및 자가면역질환 ॥의 anti-dsDNA) 공 통보고서에는 각 검사항목마다 기관에서 보고한 검사결과들의 기 준분류(시약회사) 및 세분류(장비)별 통계를 제시하였다. 정성검 사 기관별 보고서에는 참여기관의 검사결과, intended response 및 평가결과를 제시하였다. 평가는 협회의 정성검사 판정기준 에 따라 결과를 보고한 기관 중 $80 \%$ 이상의 일치를 보이는 결과 를 intended response로 하였다. 따라서 ANA pattern의 경우 $80 \%$ 이상의 일치를 보이는 결과를 intended response로 하였 다. ANA titer의 경우 최빈도 titer \pm 1 titer 빈도의 합이 $80 \%$ 이 상인 경우, 최빈도 titer \pm 1 titer를 intended response로 하였 다. 그러나 ANA pattern 및 titer는 교육목적으로 시행하였으므로 응답결과를 평가하지는 않았다.

자가면역질환 프로그램의 정량검사(자가면역질환 II의 anti$\mathrm{Tg}$, anti-TPO) 공통보고서에는 각 검사항목마다 기관에서 보고한 검사결과들의 기준분류 및 세분류별 통계를 제시하였다. 각 분류 별 참여기관 수(N), 평균(mean), 표준편차(standard deviation, $\mathrm{SD})$, 변이계수(coefficient of variations, CV), 중앙값(median), 최소값(min), 최대값(max)을 제시하였다[2]. 평균, $\mathrm{SD}, \mathrm{CV}$ 는 해 당분류별 분석에서 75 percentile 값(Q3)과 25 percentile 값 (Q1)의 차(Q3-Q1; interquartile range, IQR)의 1.5배를 초과하 여 Q1보다 낮거나, Q3보다 높은 결과값 $(<\mathrm{Q} 1-1.5 \mathrm{IQR}$ 또는 > $\mathrm{Q} 3+1.5 \mathrm{IQR}$ )은 이상치(outlier)로 제거한 후 다시 분석한 값을 제

Table 4. Results of proficiency tests for the ANA pattern

\begin{tabular}{|c|c|c|c|c|c|c|c|c|}
\hline \multirow[b]{2}{*}{ Trial } & \multirow{2}{*}{$\begin{array}{l}\text { No. of } \\
\text { partici- } \\
\text { pants }\end{array}$} & \multirow[b]{2}{*}{ Specimen } & \multirow[b]{2}{*}{ Negative } & \multicolumn{5}{|c|}{ Positive } \\
\hline & & & & Speckled & Homogenous & $\begin{array}{c}\text { Centro- } \\
\text { mere }\end{array}$ & $\begin{array}{l}\text { Cyto- } \\
\text { plasmic }\end{array}$ & Other \\
\hline \multirow[t]{3}{*}{2018,1 st } & 74 & IA1-18-01 & 0 & $74(100.0)$ & 0 & 0 & 0 & 0 \\
\hline & & IA1-18-02 & $74(100.0)$ & 0 & 0 & 0 & 0 & 0 \\
\hline & & IA1-18-03 & 0 & 0 & $74(100.0)$ & 0 & 0 & 0 \\
\hline \multirow[t]{3}{*}{2018,2 nd } & 72 & IA1-18-06 & $1(1.4)$ & 0 & $71(98.6)$ & 0 & 0 & 0 \\
\hline & & IA1-18-07 & $72(100.0)$ & 0 & 0 & 0 & 0 & 0 \\
\hline & & IA1-18-08 & 0 & $71(98.6)$ & 0 & 0 & 0 & $1(1.4)$ \\
\hline \multirow[t]{3}{*}{2019,1 st } & 77 & IA1-19-01 & $75(97.4)$ & 0 & $2(2.6)$ & 0 & 0 & 0 \\
\hline & & IA1-19-02 & 0 & $5(6.5)$ & $71(92.2)$ & 0 & 0 & 1 (1.3) \\
\hline & & IA1-19-03 & 0 & $77(100.0)$ & 0 & 0 & 0 & 0 \\
\hline \multirow[t]{3}{*}{ 2019, 2nd } & 77 & IA1-19-06 & $76(98.7)$ & 0 & $1(1.3)$ & 0 & 0 & 0 \\
\hline & & IA1-19-07 & 0 & $2(2.6)$ & $74(96.1)$ & 0 & 0 & $1(1.3)$ \\
\hline & & IA1-19-08 & 0 & $77(100.0)$ & 0 & 0 & 0 & 0 \\
\hline
\end{tabular}

Values are presented as number (\%), unless otherwise stated. The ANA pattern was an educational challenge. The most frequent responses are indicated in bold.

Abbreviation: ANA, anti-nuclear antibody. 


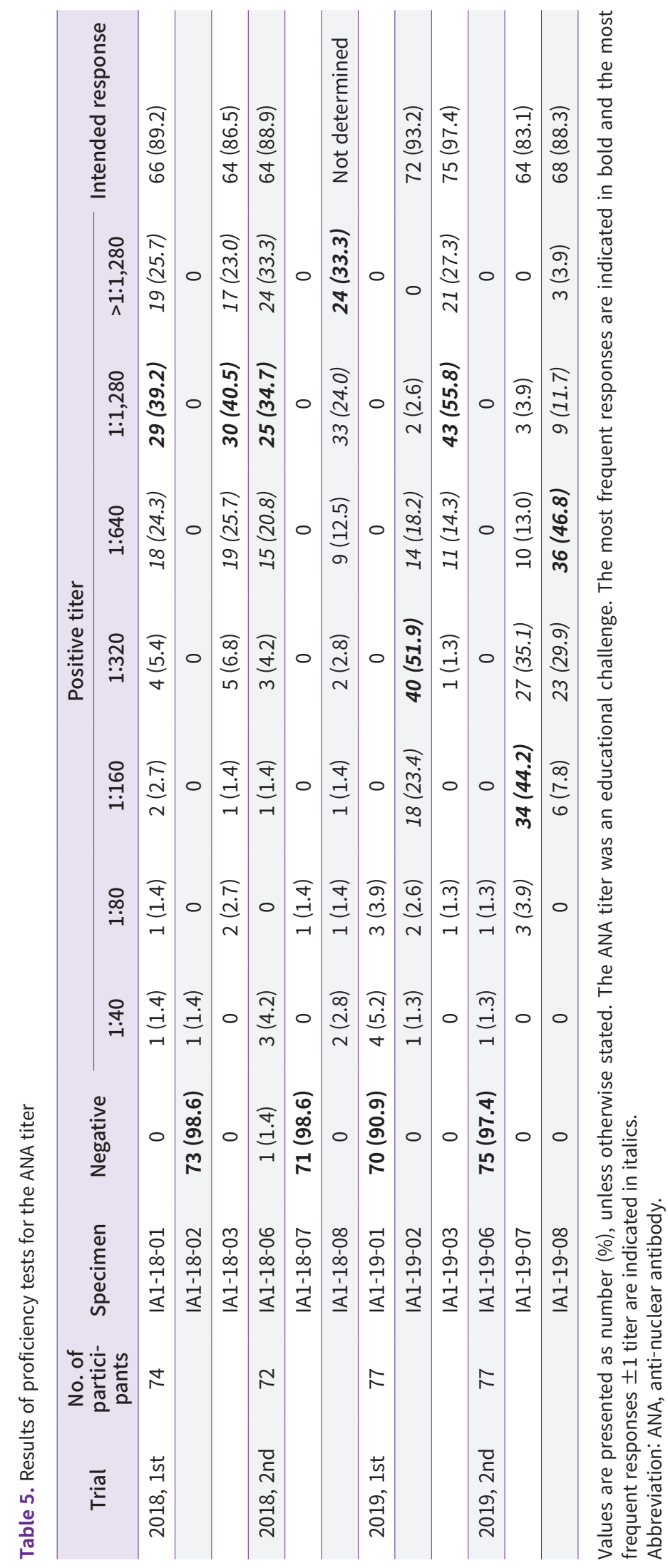




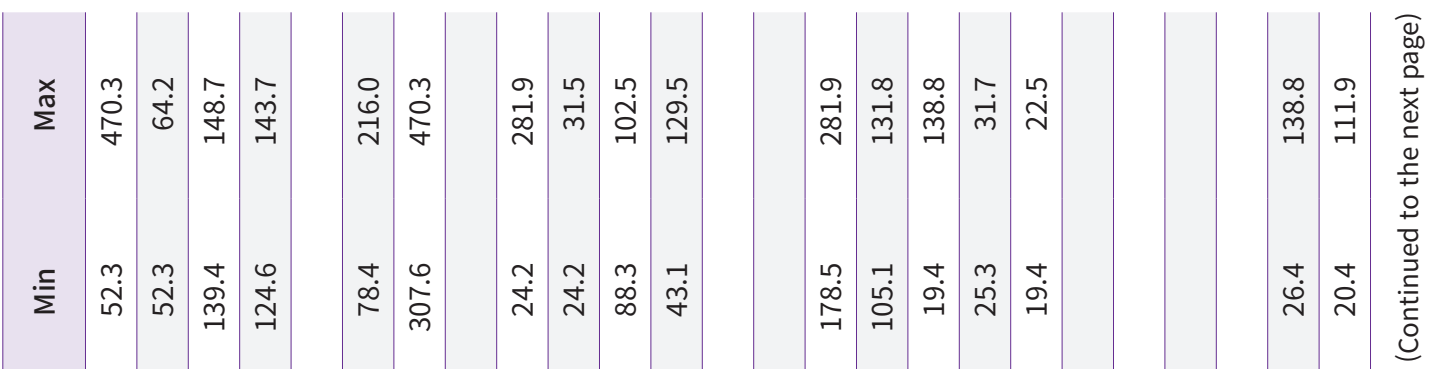

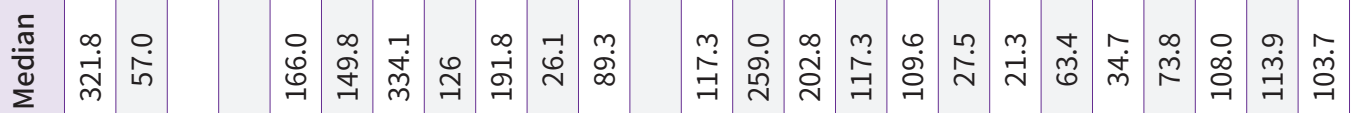

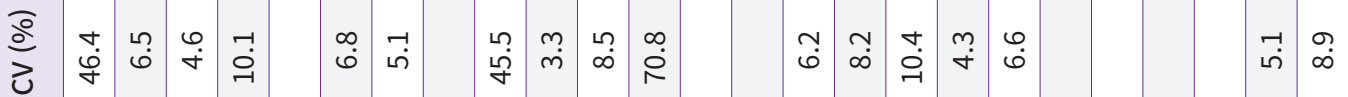

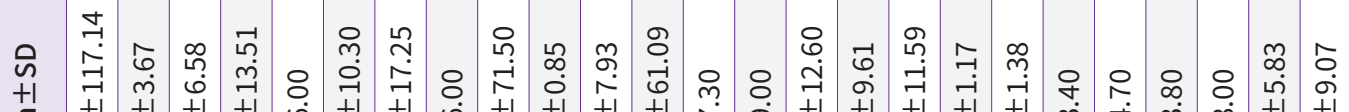

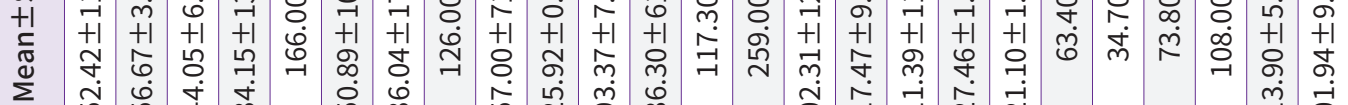

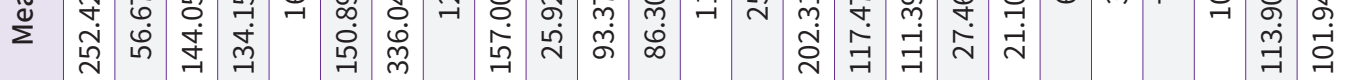

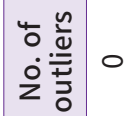

$0 \quad \stackrel{\infty}{\rightarrow}$

ङ

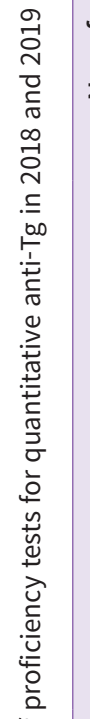

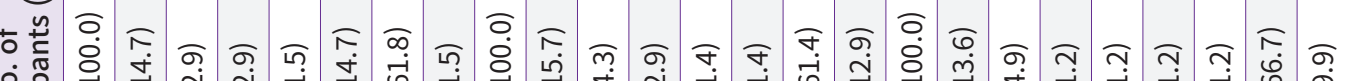

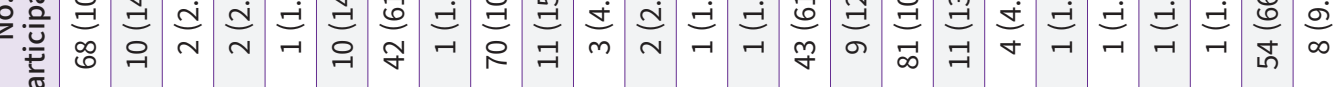

品

|

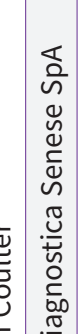

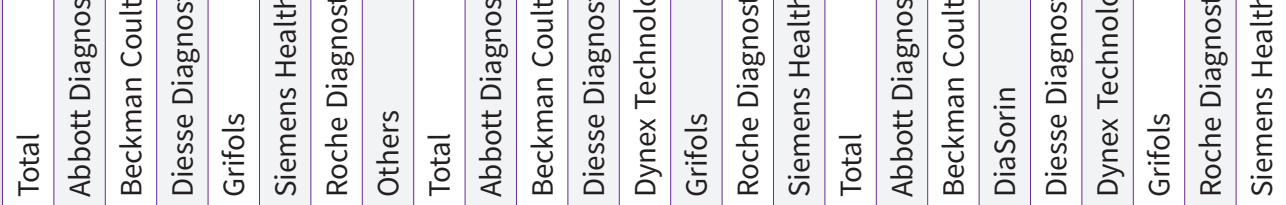

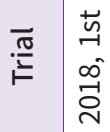

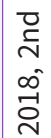

苟 


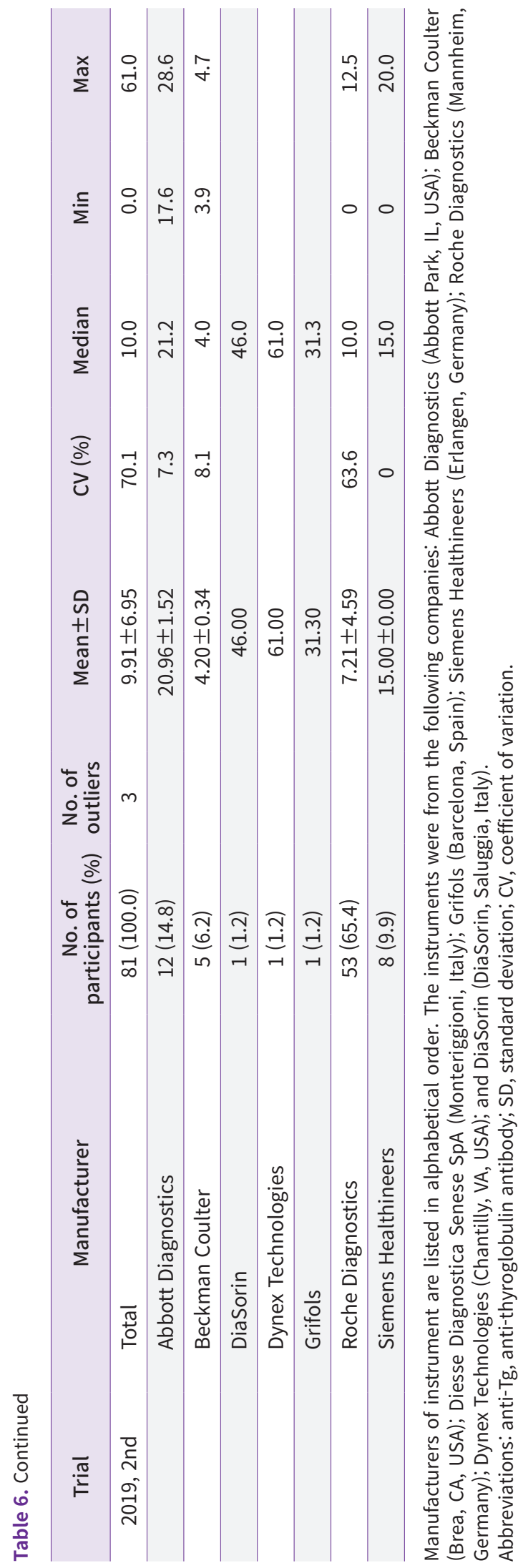

시하였다[3]. 각 분류에 해당하는 기관 수가 10 개 미만인 경우에 는 평균, SD, CV, 표준편차지수(standard deviation index, SDI) 를 제시하지 않았고, 기관 수가 3 개 미만인 경우에는 $\min , \max$ 값만 제시하였다. 정량검사 기관별 보고서에는 전체기관 및 프로 그램에 따른 기준분류의 히스토그램과 최대 12 개까지 누적된 SDI 를 표시하는 Levey Jennings 차트 및 각 기관의 결과를 기준분류 및 세분류로 제시하고, SDI 평가결과를 제시하였다. 평가는 협회 기준에 따라 기준분류, 세분류 SDI 값의 \pm 3 이내를 acceptable 로 판단하였다.

\section{결과 및 고찰}

\section{1. 참여기관 수}

자가면역질환 I 신빙도프로그램의 응답기관 수는 검사항목마다 차이가 있으나 참여기관 수가 가장 많은 ANA를 기준으로 2018년 1차 74기관, 2018년 2차 72기관, 2019년 1-2차 77기관이었다 (Table 3). 자가면역질환 II 신빙도프로그램의 경우에는 anti- $\mathrm{Tg}$ 를 기준으로 2018년 1차 68기관, 2018년 2차 70기관, 2019년 1차 와 2차 모두 81 기관이었다.

\section{2. 응답기관 결과 분포}

참여기관의 정답률은 검사항목별로 큰 차이를 나타내었다. 총 4회의 신빙도조사 결과를 통합하여 관찰하였을 때, 정성 검사의 정답률은 $\mathrm{ANA}$ 의 경우 $97.5 \%-100.0 \%, \mathrm{AMA}$ 의 경우 $88.2 \%-100.0 \%$, SMA의 경우 $85.0 \%-100.0 \%$, anti-dsDNA의 경우 $90.4 \%-100.0 \%$ 이었다(Table 3). 교육목적으로 시행한 ANA pattern과 titer의 응답기관 결과 분포는 표로 나타내었다(Tables 4, 5). Table 4와 Table 5에서 최빈도 응답을 굵은 글씨로 표현하 였다. Table 5에서 ANA 응답 중 최빈도 titer \pm 1 titer를 이탤릭체 로 표현하였다. 정량검사의 참여기관 CV는 anti-TPO가 anti-Tg 보다 작았다. Anti-Tg의 참여기관 CV는 2018년 1차 46.4\%, 2018 년 2차 45.5\%, 2019년 1차 10.4\%, 2019년 2차 70.1\%로 회차별 로 차이가 컸다(Table 6). Anti-TPO의 참여기관 CV는 2018년 1 차 16.6\%, 2018년 2차 18.6\%, 2019년 1차 21.0\%, 2019년 2차 $18.5 \%$ 로 비교적 일정한 수준을 유지하였다(Table 7).

\section{3. 정량검사 측정장비 사용현황}

참여기관이 anti-Tg와 anti-TPO 측정에 이용한 자동분석장 비를 제조사별로 분류하였다. 회차별로 anti- $\mathrm{Tg}$ 의 경우 2018 년 Roche (Roche Diagnostics, Mannheim, Germany)가 $61.6 \%$ 로 가장 많았고, Abbott (Abbott Diagnostics, Abbott Park, IL, USA) 15.2\%, Siemens Healthineers (Siemens 
Table 7. Results of proficiency tests for quantitative anti-TPO in 2018 and 2019

\begin{tabular}{|c|c|c|c|c|c|c|c|c|}
\hline Trial & Manufacturer & $\begin{array}{c}\text { No. of } \\
\text { participants } \\
(\%)\end{array}$ & $\begin{array}{l}\text { No. of } \\
\text { out- } \\
\text { liers }\end{array}$ & Mean $\pm S D$ & CV (\%) & Median & Min & Max \\
\hline \multirow[t]{8}{*}{$2018,1 s t$} & Total & $61(100.0)$ & 9 & $146.78 \pm 24.31$ & 16.6 & 144.5 & 77.2 & 370.3 \\
\hline & Abbott Diagnostics & $10(16.4)$ & & $181.97 \pm 11.78$ & 6.5 & 180.4 & 168.7 & 199.0 \\
\hline & Beckman Coulter & $4(6.6)$ & & $120.75 \pm 1.62$ & 1.3 & 121.1 & 118.7 & 122.1 \\
\hline & Diesse Diagnostica Senese SpA & $2(3.3)$ & & $241.15 \pm 73.75$ & 30.6 & & 189.0 & 293.3 \\
\hline & Grifols & $1(1.6)$ & & 146.00 & & 146.0 & & \\
\hline & Roche Diagnostics & $34(55.7)$ & & $138.99 \pm 8.30$ & 6.0 & 139.9 & 124.0 & 199.2 \\
\hline & Siemens Healthineers & $9(14.8)$ & & $355.33 \pm 13.76$ & 3.9 & 358.9 & 77.2 & 370.3 \\
\hline & Others & $1(1.6)$ & & 132.00 & & 132.0 & & \\
\hline \multirow[t]{8}{*}{ 2018, 2nd } & Total & $64(100.0)$ & 9 & $75.95 \pm 14.10$ & 18.6 & 80.4 & 41.0 & 394.0 \\
\hline & Abbott Diagnostics & $11(17.2)$ & & $66.47 \pm 3.59$ & 5.4 & 67.0 & 60.3 & 72.6 \\
\hline & Beckman Coulter & $4(6.3)$ & & $44.10 \pm 2.72$ & 6.2 & 44.0 & 41.0 & 47.4 \\
\hline & Diesse Diagnostica Senese SpA & $2(3.1)$ & & $77.95 \pm 38.25$ & 49.1 & & 50.9 & 105.0 \\
\hline & Dynex Technologies & $1(1.6)$ & & 92.00 & & 92.0 & & \\
\hline & Grifols & $1(1.6)$ & & 89.60 & & 89.6 & & \\
\hline & Roche Diagnostics & $37(57.8)$ & & $81.45 \pm 8.50$ & 10.4 & 82.3 & 61.5 & 394.0 \\
\hline & Siemens Healthineers & $8(12.5)$ & & $207.89 \pm 16.42$ & 7.9 & 203.7 & 187.4 & 232.1 \\
\hline \multirow[t]{10}{*}{$2019,1 s t$} & Total & $80(100.0)$ & 11 & $18.16 \pm 3.81$ & 21.0 & 19.7 & 9.7 & 114.2 \\
\hline & Abbott Diagnostics & $13(16.3)$ & & $18.10 \pm 1.33$ & 7.4 & 17.6 & 15.6 & 19.7 \\
\hline & Beckman Coulter & $5(6.3)$ & & $12.33 \pm 0.12$ & 0.9 & 12.4 & 11.7 & 13.3 \\
\hline & bioM rieux & $1(1.3)$ & & 9.70 & & 9.7 & & \\
\hline & DiaSorin & $1(1.3)$ & & 28.60 & & 28.6 & & \\
\hline & Diesse Diagnostica Senese SpA & $1(1.3)$ & & 17.60 & & 17.6 & & \\
\hline & Dynex Technologies & $1(1.3)$ & & 42.60 & & 42.6 & & \\
\hline & Grifols & $1(1.3)$ & & 31.20 & & 31.2 & & \\
\hline & Roche Diagnostics & $48(60.0)$ & & $18.78 \pm 3.61$ & 19.2 & 19.9 & 11.8 & 114.2 \\
\hline & Siemens Healthineers & $9(11.3)$ & & $77.66 \pm 5.54$ & 7.1 & 76.8 & 17.1 & 91.7 \\
\hline \multirow[t]{9}{*}{ 2019, 2nd } & Total & $81(100.0)$ & 9 & $120.58 \pm 22.33$ & 18.5 & 115.0 & 2.5 & 897.3 \\
\hline & Abbott Diagnostics & $14(17.3)$ & & $157.41 \pm 8.31$ & 5.3 & 159.6 & 144.2 & 170.6 \\
\hline & Beckman Coulter & $6(7.4)$ & & $106.06 \pm 4.07$ & 3.8 & 105.2 & 2.5 & 110.1 \\
\hline & bioM rieux & $1(1.2)$ & & 97.60 & & 97.6 & & \\
\hline & DiaSorin & $1(1.2)$ & & 167.00 & & 167.0 & & \\
\hline & Dynex Technologies & $1(1.2)$ & & 132.00 & & 132.0 & & \\
\hline & Grifols & $1(1.2)$ & & 154.00 & & 154.0 & & \\
\hline & Roche Diagnostics & $48(59.3)$ & & $109.44 \pm 9.19$ & 8.4 & 111.9 & 91.5 & 131.3 \\
\hline & Siemens Healthineers & $9(11.1)$ & & $780.85 \pm 78.07$ & 10.0 & 737.9 & 144.0 & 897.3 \\
\hline
\end{tabular}

Manufacturers of instrument are listed in alphabetical order. The instruments were from the following companies: Abbott Diagnostics (Abbott Park, IL, USA); Beckman Coulter (Brea, CA, USA); Diesse Diagnostica Senese SpA (Monteriggioni, Italy); Grifols (Barcelona, Spain); Roche Diagnostics (Mannheim, Germany); Siemens Healthineers (Erlangen, Germany); Dynex Technologies (Chantilly, VA, USA); bioM rieux (bioM rieux, Marcy-l'Etoile, France); and DiaSorin (DiaSorin, Saluggia, Italy).

Abbreviations: anti-TPO, anti-thyroperoxidase antibody; SD, standard deviation; CV, coefficient of variation. 
Healthcare, Erlangen, Germany) 13.8\%, Beckman Coulter (Beckman Coulter, Brea, CA, USA) 3.6\%, Diesse (Diesse Diagnostica Senese SpA, Monteriggioni, Italy) 2.9\%, Dynex Technologies (Dynex Technologies, Chantilly, VA, USA) 와 Grifols (Grifols, Barcelona, Spain)가 각각 $1.4 \%$ 순이 었다. 2019년에는 Roche $66.0 \%$, Abbott $14.2 \%$, Siemens Healthineers 9.9\%, Beckman Coulter 5.6\%, Grifols, DiaSorin (DiaSorin, Saluggia, Italy), Dynex Technologies 이 각각 $1.2 \%$, Diesse $0.6 \%$ 순으로 변경되었다. Anti-TPO 경 우 2018년 Roche가 56.8\%로 가장 많았고, Abbott $16.8 \%$, Siemens Healthineers 13.6\%, Beckman Coulter 6.4\%, Diesse 3.2\%, Dynex Technologies와 기타 제조사가 각각 0.8\% 순이었다. 2019년에는 Roche 59.6\%, Abbott 16.8\%, Siemens Healthineers $11.2 \%$, Beckman Coulter 6.8\%, bioM rieux (bioM rieux, Marcy-l'Etoile, France), DiaSorin, Dynex Technologies, Grifols가 모두 1.2\%, 마지막으로 Diesse 0.6\% 순으로 변경되었다.

\section{4. 결과 해석상 주의할 점}

정성검사의 경우 동일한 시약이나 장비를 사용하는 기관의 수 가 적거나 $80 \%$ 이상의 합의된 결과가 나오지 않는다면 정답을 판 정하기 어려운 경우가 있는데, 지속적으로 이와 같은 결과가 나오 는 시약에 대해서는 회사나 기관차원에서 추가 대책 마련이 필요
할 수 있다. 2018-2019 자가면역검사 신빙도조사 프로그램 I, II 에서 정성검사의 경우 intended response로 응답한 참여기관이 $88.2 \%-100.0 \%$ 로 우수한 성적을 나타내었다. 교육목적으로 시 행한 ANA pattern은 intended response로 응답한 참여기관이 92.2\%-100.0\%로 우수하였다. 교육목적으로 시행한 ANA titer 는 20018-2019 4회차 중 8개의 positive 검체에 대하여 titer를 평가할 수 있었다. 2018 2회차 IA1-18-08 검체의 경우 최빈도 응 답 titer는 >1:1,280의 최고 농도였고 \pm 1 titer 응답기관이 $80 \%$ 미만인 79.2\% (57/72)로 intended response를 결정할 수 없 었다. 나머지 7개 positive 검체에 대한 ANA titer는 intended response로 응답한 기관이 $83.1 \%-97.4 \%$ 로 관찰되었다. 향후 교육목적의 신빙도조사항목을 지속적으로 유지하여 변화 및 효과 를 지켜볼 필요가 있다.

2018년부터 확장 및 개편되어 시행된 자가면역검사 프로그램 은 차세대 신빙도조사사업 운영방침에 따라 전 과정이 임상검사 정도관리협회 중앙에서 일괄 시행되었는데, 참여기관은 일부 항목 에서 전년에 비해 증가하였다. 자가면역검사 프로그램은 참여기관 수가 100 개 미만으로 비교적 적은 것이 특징이며, 동료그룹이 적 은 경우에는 외부정도관리 결과를 신중하게 해석할 필요가 있다. 이 신빙도조사 통계분석 자료는 각 기관에서 외부정도관리 결과를 해석할 때 도움을 주고, 검사실에서 자가면역검사를 새로 시작할 때 유용한 자료로 사용될 것으로 기대한다.

\section{REFERENCES}

1. Park HD. Annual Report on the External Quality Assessment Scheme for Special Protein in Korea (2017). J Lab Med Qual Assur 2018;40:85-91.

2. Klee GG, Westgard JO. Quality management. In: Burtis CA, Ashwood ER, Bruns DE, editors. Teitz textbook of clinical chemistry and molecular diagnostics. 5th ed. St. Louis (MO): Elsevier Saunders, 2012:163-203.

3. Turkey JW. Exploratory data analysis. Reading (MA): Addison-Wesley, 1977. 